\title{
Effect of Watershed Subdivision and Antecedent Moisture Condition on HEC-HMS Model Performance in the Maha Oya Basin, Sri Lanka
}

\author{
${ }^{1^{*}}$ M. Kamran, ${ }^{2}$ RL.H.L. Rajapakse \\ ${ }^{1}$ Research Assistant at UNESCO Madenjeet Singh Centre for South Asia Water Management, University of \\ Moratuwa, Sri Lanka \\ Senior Lecturer at Department of Civil Engineering, University of Moratuwa, Sri Lanka \\ "Email: kamran.muhammad229@gmail.com
}

\begin{abstract}
In large scale watersheds, the accuracy level of medium and low flow simulation could decrease due to uncertainty of the watershed parameters. In hydrological modeling, sub division of watershed would help to better implement decision-making related to water resources management, which relies heavily on hydrologic simulations. However, an important concern will be raised over problems associated with lumped hydrologic models with watershed subdivision broadly applied in so called semi-distributed hydrological models since scale issues would significantly affect model performance, and thus, lead to dramatic variations in simulation results. It is important to achieve the appropriate level of sub divisions (discretization). Further at times, the resulting flood level can be much higher than expected, due to storm events. This is unprecedented and the reason may be due to saturated moisture level in the soil layer. Therefore, the Antecedent Moisture Condition (AMC) is an important parameter to be investigated to check the accuracy and possibility of further improvement of the model. In this paper, Hydrologic Modeling System (HEC-HMS) was used for continuous simulation to investigate the effect of watershed subdivision on the model performance. Further, the antecedent moisture condition (AMC) events were used to study the impacts of AMC on the model performance. Badalgama watershed is selected as study area in Maha Oya Basin in Sri Lanka. Spatial extents of Maha Oya Basin and Badalgama watershed are $1553 \mathrm{~km}^{2}$ and $1272 \mathrm{~km}^{2}$, respectively. Four rainfall stations and one river gauging station were selected in Badalgama watershed. Nash-Sutcliffe (NASH) coefficient and Mean Ratio of Absolute Error (MRAE) were selected as objective functions for modeling. The main focus was on MRAE, as the objective function, but Nash coefficient was also estimated and checked for comparison. In particular, results show that generally the accuracy of the model decreased from six to sixteen sub divisions, which shows that variation in the total number of sub watersheds had very little effect on runoff hydrographs and improvements generally disappear when the number of subdivisions reaches a relatively small number, approximately between six and sixteen sub-watersheds. The accuracy of the model with AMC-III increased by $12.04 \%$ when compared to AMC-II hence showing more reliable results as compared with AMC-II condition. In this research, recession method was used for base flow estimation, which led to mass balance error exceeding $20 \%$. Therefore it is recommended that for improving the accuracy, linear reservoir method for base flow estimation should be used in order to conserve the water balance and AMC-III should be used for fully saturated soil instead of AMC-II.
\end{abstract}

Indexed Terms- Antecedent moisture condition; HEC HMS; Watershed sub-division; Sensitivity analysis 


\section{INTRODUCTION}

It has been stated that watershed is treated to be homogenous with its representative parameters (land use, soil type, etc.) in a lumped hydrologic model. However, with the large watershed size, the homogeneity can be affected because larger watersheds are more likely to have variable conditions within the watershed [1]. Due to large watershed size, rainfall runoff modeling as a single lumped model might lead to poor simulation results. Watershed subdivision is usually used in semi-distributed hydrologic models to capture spatial heterogeneities of distributed land cover and soil datasets and to characterize distributed inputs in different areas within the watershed. The antecedent moisture condition (AMC) is defined as the initial moisture condition of the watershed prior to the storm event of interest. Normally, AMC II is taken as the base condition with reference to which curve numbers $(\mathrm{CN})$ are adjusted. It describes the watershed's "average condition" in terms of wetness and the corresponding $\mathrm{CN}$ but when the soil is fully saturated, AMC-III becomes prevalent as compared to AMC-II. Therefore, this study was carried out to check the performance of the model when the soil is full saturated. In this study, to check the performance with watershed sub division, there are two components for the hydrological modeling; the first component is to estimate the hydrologic response of a watershed as a single basin with no subdivisions and the second component is to analyze the watershed by subdividing it into 3, 6, 9, and 16 sub- basins. Minshall, (1960) [2] stated that the impact of catchment scale on hydrologic response and its importance in rainfall runoff modeling has been identified since the early 1960. Zhang.H. L, Wang, Wang, Li, \& Wang (2013) [3] had done work in Clear Creek watershed in Iowa, United States to investigate the effect of watershed scale on HECHMS calibrated parameters and concluded that the value of the key calibrated parameters are sensitive to watershed partition scheme and the watershed partition affects hydrologic processes.

For antecedent soil moisture , Zhang, Wei, \& Nearing (2011) [4] applied Rangeland Hydrology and Erosion Model (RHEM) to investigate the effect of antecedent soil moisture on runoff and concluded that Sensitivity analysis of the model showed an average of $0.05 \mathrm{~mm}$ change in runoff generation for each $1 \%$ change in soil moisture, indicating an approximate $0.15 \mathrm{~mm}$ average variation in runoff accounted for by the 3\% standard deviation of measured antecedent soil moisture. The Soil Conservation Service Curve Number (SCS-CN) method (SCS 1956, 1964, 1971, 1993) converts rainfall to surface runoff (or rainfall-excess) using curve number, which is derived from watershed characteristics and 5-day antecedent rainfall. Based on the work of Williams \& Laseur (1976) [5], Hawkins (1978) [6] proposed a procedure for CN adjustment with the watershed's moisture status, specifically to eliminate the above quantum jump in $\mathrm{CN}$ values from one $\mathrm{AMC}$ to other.

\section{MATERIALS AND METHODOLOGY}

\subsection{Study Site}

The Maha Oya is a major stream in the Sabaragamuwa Province of Sri Lanka. It measures approximately $134 \mathrm{~km}(83 \mathrm{mi})$ in length. It runs across four provinces and five districts. Maha Oya has 14 water supply networks to serve the need of drinking water and more than 1 million people live by the river. Its catchment area receives approximately 3,644 million cubic meters of rain per year, and approximately 34 percent of the water reaches the sea. It has a catchment area of $1,510 \mathrm{~km}^{2}$. In this study, Badalgama watershed is selected as shown in Figure 1. Badalgama watershed is a sub watershed of Maha Oya Basin and drainage area 1,272 $\mathrm{km}^{2}$. 


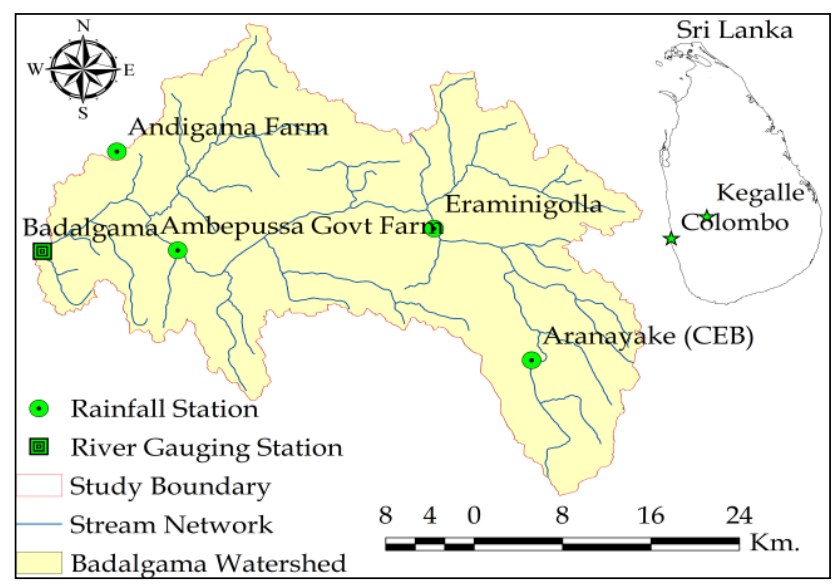

Figure 1: Study area map

\subsection{Rainfall and streamflow data}

In this study area, there is one river gauging station at Badalgama and four rainfall gauging stations namely, Ambepussa Govt. Farm, Andigama Farm, Aranayake (CEB), and Eraminigolla which are located within the study area. Rainfall data was collected for the period 2005-2013 from Meteorological Department, Colombo and from this data set, 2009 year data was excluded because due to 9 month missing data in this year. Therefore, the data set was divided for calibration (20052008) and for validation (2010-2013) based on this break point. Daily streamflow data was collected from Irrigation Department, Colombo and the soil and land use map (1:50,000) were collected from survey Department, Sri Lanka. Missing data were filled with slope method based on regression analysis or replaced with the value at neighboring station with a slope factor. Missing values are either replaced directly by the value at the neighbor station or adjusted by a factor [7]. After filling in the missing data, consistency and homogeneity of the series were checked with single mass curve and double mass curve and further the annual mass balance was also checked.

\subsection{HEC-HMS Model and Parameters}

HEC-HMS model is designed to simulate the complete hydrological processes of a dendritic watershed system and can be used for both continuous and event-based modeling. In HEC HMS, out of 11 available loss methods, only 3 loss methods can be used for continues simulation. The soil moisture accounting (SMA) algorithm has been successfully used in continuous simulation of the model [8]. In this study, the soil moisture accounting method was used. Table 1 provides a list of different parameter methods selected in the watershed.

Table 1: Model selection in HEC -HMS

\begin{tabular}{lc}
\hline \multicolumn{1}{c}{ PARAMETER METHOD } & BASIN MODEL \\
\hline CANOPY METHOD & SELECTED METHOD \\
SURFACE METHOD & None \\
TRANSFORM METHOD & None \\
BASE FLOW METHOD & Clark unit hydrograph \\
ROUTING METHOD & Recession \\
LOSS METHOD & Muskingum \\
\hline
\end{tabular}




\subsubsection{Evaluation of the model}

Hydrologic simulation models are calibrated by comparing observed data against the data generated by the models. The comparison is made following an optimization procedure using an objective function adopted for that purpose and a set of data which is a subset of all data available or observable.. In this study, two objective functions were selected for model evaluation base on the purpose of the study. Nash-Sutcliffe (NASH) and Mean Ratio of Absolute Error (MRAE) were selected as objective function for modeling. The main focus was on MRAE, as the objective function, but Nash coefficient was also estimated and checked for comparison. Wijesekera \& Abeynayake (2003)[9] defined that Mean Ratio of Absolute Error (MRAE) is the difference between calculated and observed flow with respect to that particular observation.

$$
\operatorname{MRAE}=\frac{1}{\mathrm{n}}\left[\sum \frac{\left|\mathrm{Q}_{\mathrm{obs}}-\mathrm{Q}_{\mathrm{cal}}\right|}{\mathrm{Q}_{\mathrm{obs}}}\right]
$$

where

$Q_{o b s}$ is the observed streamflow and $Q_{c a l}$ is the calculated streamflow, and $n$ is the number of observations used for comparison.

The Nash-Sutcliffe efficiency (E) is a widely used and potentially reliable statistic for assessing the goodness of fit of hydrologic models [10]

$$
\mathrm{NSE}=1-\left(\sum_{i=1}^{N}\left(\mathrm{~S}_{\mathrm{i}}-\mathrm{O}_{\mathrm{i}}\right)^{2} / \sum_{\mathrm{i}=1}^{\mathrm{N}}\left(\mathrm{O}_{\mathrm{i}}-\mathrm{O}_{\text {mean }}\right)^{2}\right)
$$

where

$S_{\mathrm{i}}=$ model simulated output; $O_{\mathrm{i}}=$ observed hydrologic variable; $O_{\text {mean }}=$ mean of the observations that the NSE uses as a benchmark against which performance of the hydrologic model is compared; and $N$ $=$ total number of observations.

\subsubsection{Parameters Sensitivity Analysis}

Initial parameters were selected following the methodology reported by De Silva, Weerakoon, \& Herath, (2014) [11] in Kelani Basin Sri Lanka. After attempting manual and automatic adjustment of the parameters, the sensitivity analysis of the parameters was performed to check the behavior of the parameters.

The sensitivity analysis was used to determine the appropriate range of parameters for model calibration. Initially, the model was run with the initial estimated parameters, and thereafter, out of the various soil moisture accounting parameters, Clark unit hydrograph parameters and recession for base flow parameters were varied one parameter at a time and analyzed from $-50 \%$ to $50 \%$ with increments of $10 \%$, keeping all other parameters constant. Greater percentage change in the simulated volumes represents greater variable sensitivity. Figure 2 shows that the soil percolation is the most sensitive parameter and tension storage is the least sensitive parameter. 


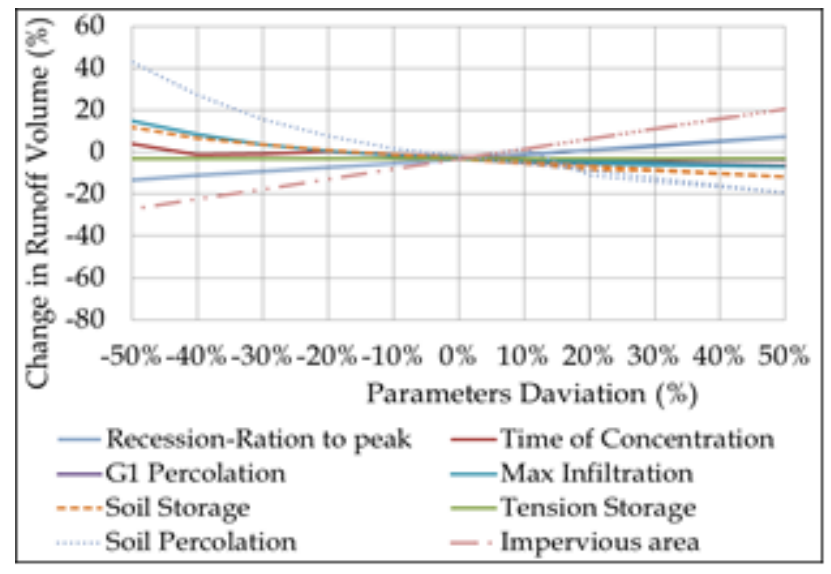

Figure 2: Parameter sensitivity analysis

\subsubsection{Global optimization}

Global optimization has been achieved manually in HEC HMS 4.0 by changing the most sensitive parameters from optimum parameter value to minimum value and maximum value of the parameters. The parameter optimization results in Figure $3 \mathrm{~s}$ show that there exists a merging and tangential effect when it reaches to the optimum limit of the parameter values.

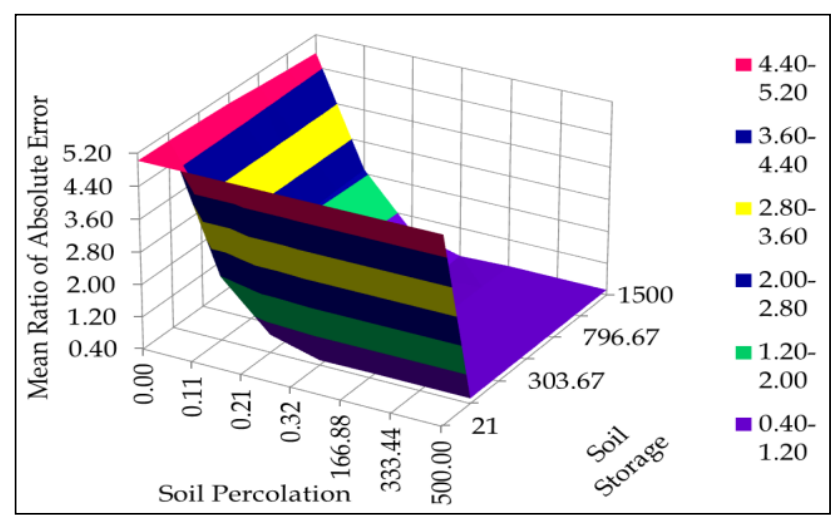

Figure 3: Global optimization of the parameters

\subsection{Watershed Subdivision}

In HEC-HMS, a river basin is divided into a number of sub watersheds based on a critical area threshold for the stream generation. The threshold is the minimum upstream drainage area for a channel to originate and can be specified by a percentage of total watershed area [12]. 


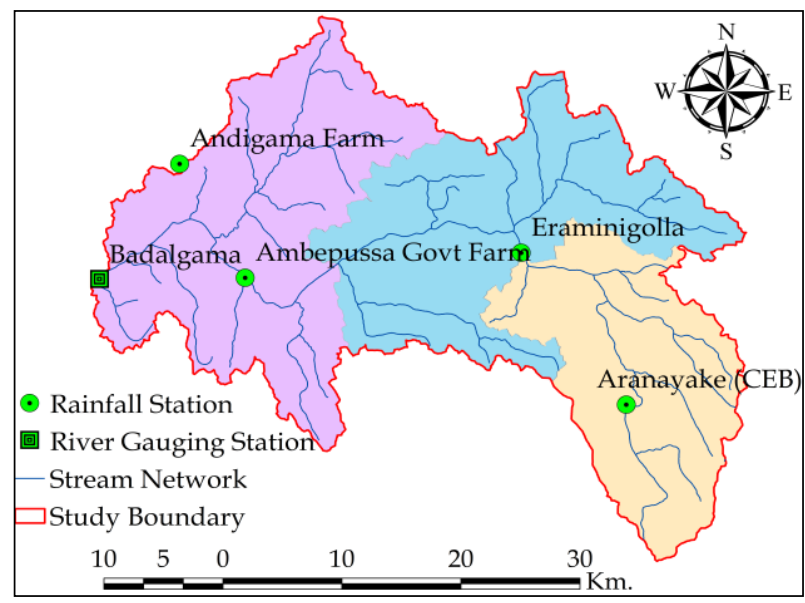

Figure 4: Three sub divisions of Badalgama watershed

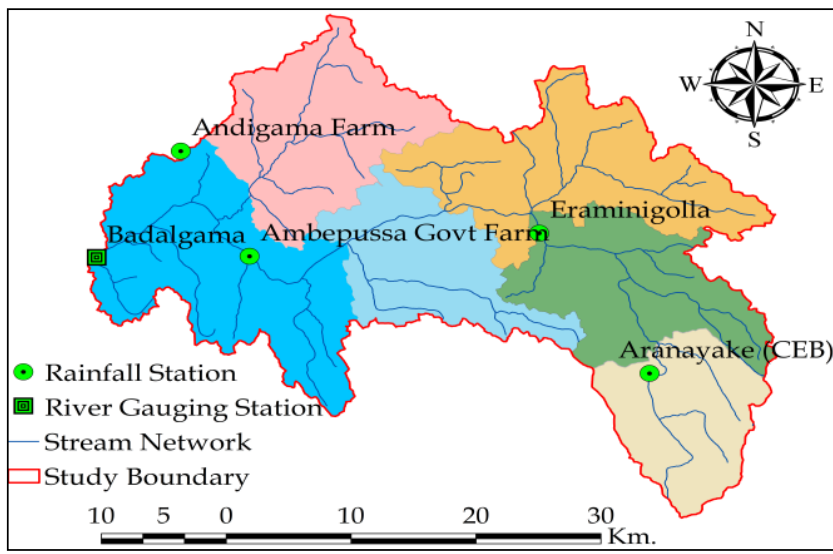

Figure 5: Six sub divisions of Badalgama watershed

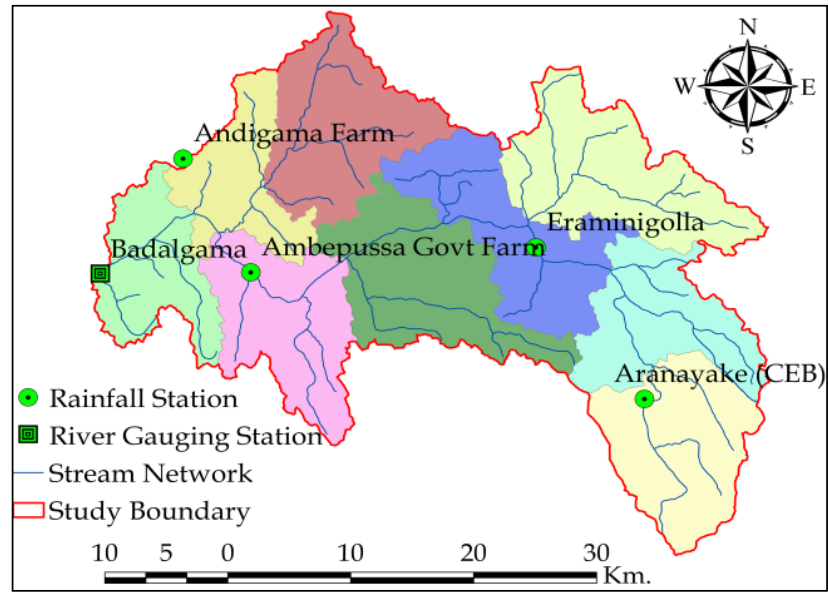

Figure 6: Nine sub divisions of Badalgama watershed 


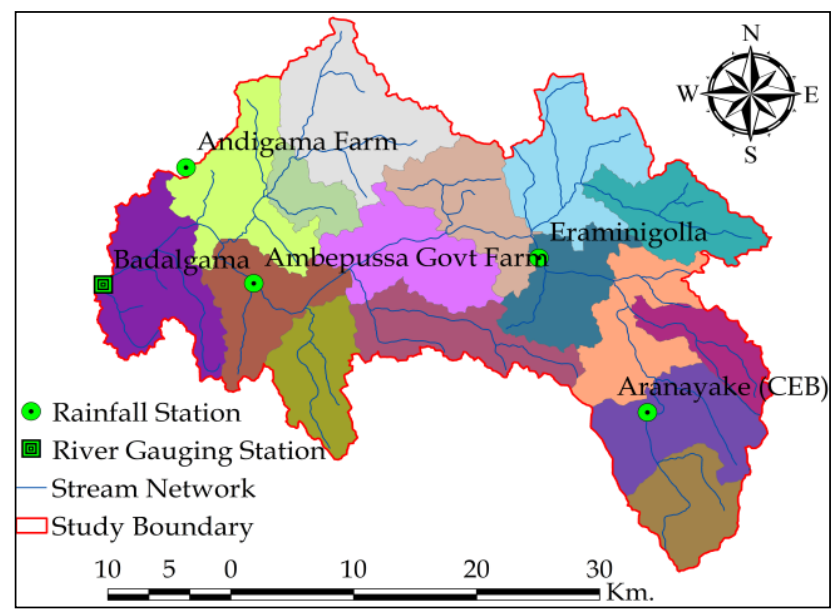

Figure 7: Sixteen sub divisions of Badalgama watershed

\subsection{Analysis of antecedent moisture condition}

To determine the application of the SCS curve number procedure in Badalgama watershed, classification of the watershed soils into appropriate hydrological groups was done according to the same methodology used by the SCS (National Engineering Handbook, Section4, (NEH-4), 1964). The classification of watershed characteristics is given in Table 3. The soil classification has been done into four hydrologic soil groups as shown in Figure 9. The land use classes adopted for curve number value is given in Table 3 .

\subsubsection{Weighted Curve Number}

A weighted curve number has been assigned for different land use types and the following equation was used for weighted curve number.

$$
\mathrm{CN}=\frac{\sum \mathrm{CN}_{1} * \mathrm{~A}_{1}+\mathrm{CN}_{2} * \mathrm{~A}_{2}+\mathrm{CN}_{\mathrm{n}} * \mathrm{~A}_{\mathrm{n}}}{\sum \mathrm{A}}
$$

where

$C N=$ Weighted mean curve number, Where $A_{1}, A_{2} \ldots A_{\mathrm{n}}$ represent areas of polygons having $C N$ values $C N_{1}, C N_{2}, \ldots ., C N_{\mathrm{n}}$ respectively and $A$ is the total area.

Table 2: Weighted Curve Number for Badalgama Watershed

\begin{tabular}{lccc}
\hline \multicolumn{1}{c}{ Land use } & Area $(\mathbf{k m})$ & Percentage $(\boldsymbol{\%})$ & Weighted Curve Number \\
\hline Agriculture & 194.920 & 15.3 & \\
Built up area & 17.259 & 1.4 & \\
Homestead & 257.177 & 20.2 & 66.39 \\
Forest & 33.141 & 2.6 & \\
Plantation & 709.928 & 55.8 & \\
Water bodies & 9.011 & 0.8 & \\
Scrub area & 49.698 & 3.9 & \\
\hline
\end{tabular}




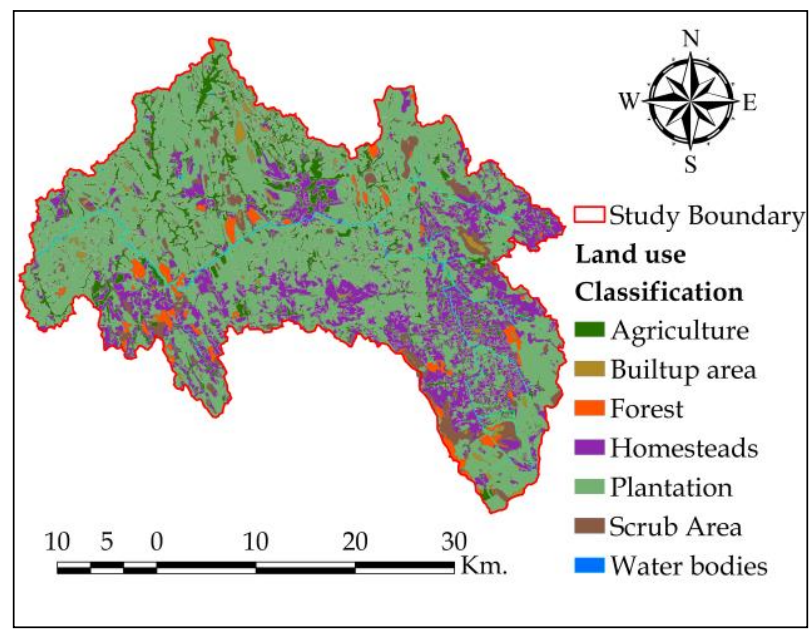

Figure 8: Land use Classification

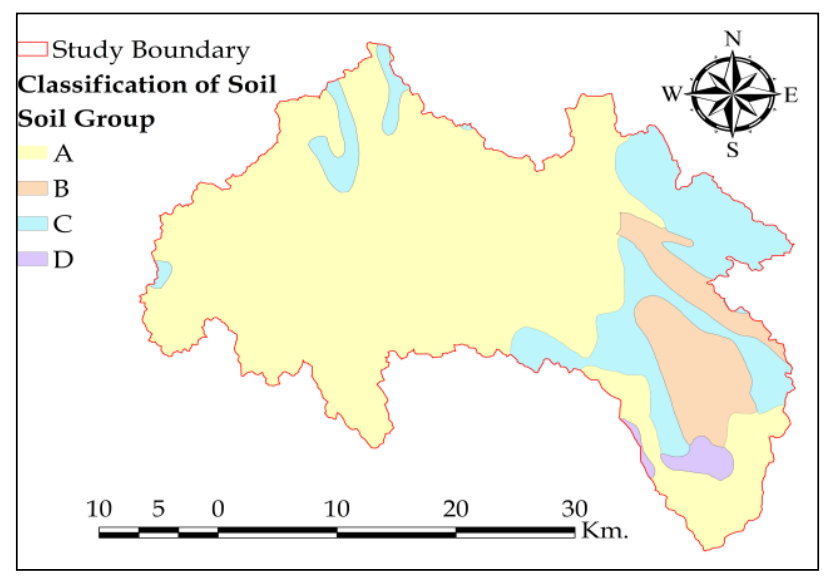

Figure 9: Watershed soil classification

\subsubsection{Calculation of Antecedent Moisture Condition}

The AMC-II was calculated using characteristic land use of Badalgama watershed which is 66.39 as given in the Table 2. Mishra had compared AMC-dependent CN-conversion formulae and treating the NEH-4 CN-values (SCS, 1972) as target values. The authors have applied different $\mathrm{CN}$-conversion formulae and concluded that Hawkins formulae to perform the best in CN-III-conversions, when compared with the NEH-4 value as target value [13]. In this study, for the calculation of AMC-I and AMC-III, Hawkins formula was used. The limits adopted for AMC-I and AMC-II and AMC-III is given in the Table 3.

Table 3: Limitation of AMC value SCS (NEH-4, 1964)

\begin{tabular}{ccc}
\hline & Total Five - days Antecedent Rainfall (cm) & \\
\hline AMC & Dormant season & Growing season \\
\hline I & Less than 1.3 & Less than 3.6 \\
II & 1.3 to 2.8 & 3.6 to 5.3 \\
III & Over 2.8 & Over 5.3 \\
\hline
\end{tabular}


Table 4: Calculations of Antecedent moisture conditions and other parameters value

\begin{tabular}{ccccccccc}
\hline & AMC1 & \multicolumn{3}{c}{ AMCII } & \multicolumn{3}{c}{ AMCIII } \\
\hline CNI & S & IA & CNII & S & IA & CNIII & S & IA \\
\hline 46.4 & 293 & 59 & 66.4 & 129 & 26 & 82.2 & 54.9 & 10.9 \\
\hline
\end{tabular}

After calculation of antecedent moisture conditions, potential maximum retention and initial abstraction were calculated as shown in Table 4. The AMC value is calculated for the data from 2010 to 2013 for lumped model and 6-subdivision model. The purpose of calculation of AMC in each subdivision was to know that which AMC conditions were prevalent. Later on, the T-test was carried out to statistically check the significant differences between the lumped model and each subdivision.

\section{RESULTS AND DISCUSSION}

\subsection{Calibration and Validation Results}

Daily rainfall data from January 2005 to 2008 December were used for calibration, and the remaining data from January 2010 to 2013 December were used to validate the model. The performance of the model with respect to simulated river flow was examined using MRAE objective function. Better model performance was deemed realized if the value of MRAE was closer to zero. In total, five model layouts were developed (i.e. lumped, 3-subdivision, 6-sub division, 9-sub division, and 16-sub division) and each of the sub division model was compared against the lumped model. The result shows that the sub division 6 model gives better results as compared to other sub division models and the lumped model. The overall result for calibration period is given in

Table 5 and graphically represented in Figure 10, Figure 11 and Table 6.

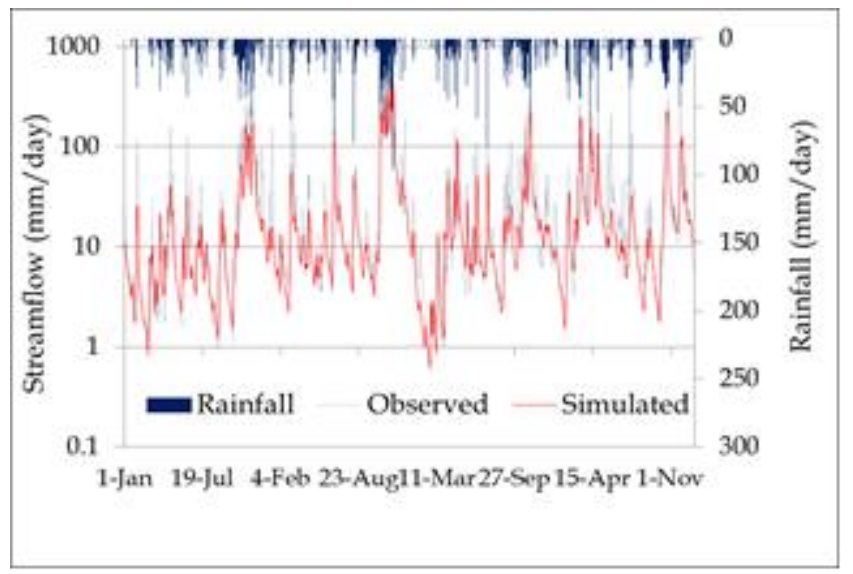

Figure 10: Calibration result for six sub division model of Badalgama watershed 
Table 5: Summary of model performance in calibration period

\begin{tabular}{ccccc}
\hline Model layout & Overall performance & High flow & Medium flow & Low flow \\
\cline { 2 - 5 } & MRAE & MRAE & MRAE & MRAE \\
\hline $\begin{array}{c}\text { Lumped Model } \\
3 \text { sub division } \\
\text { Model }\end{array}$ & 0.393 & 0.359 & 0.390 & 0.43 \\
$\begin{array}{c}6 \text { sub division } \\
\text { Model }\end{array}$ & 0.385 & 0.363 & 0.390 & 0.442 \\
$\begin{array}{c}9 \text { sub division } \\
\text { Model }\end{array}$ & 0.375 & 0.353 & 0.383 & 0.368 \\
16 sub division \\
Model
\end{tabular}

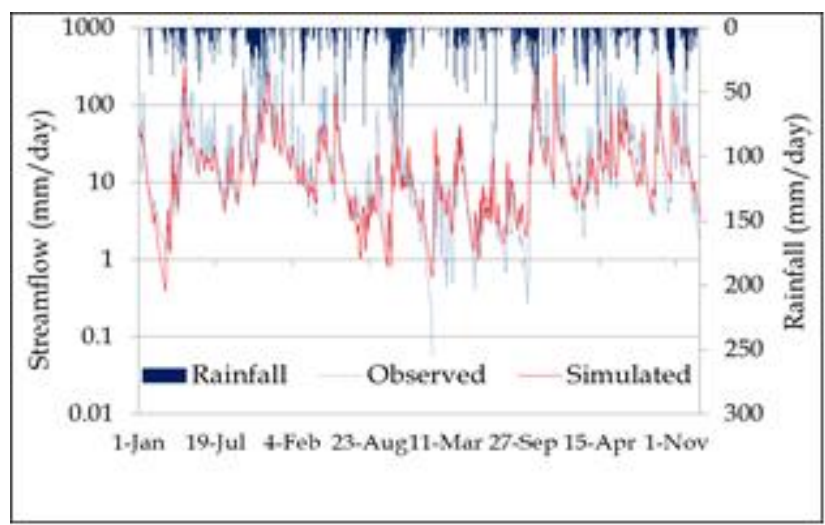

Figure 11: Validation result for six sub division model of Badalgama watershed

Table 6: Summary of model performance in validation period

\begin{tabular}{ccccc}
\hline \multirow{2}{*}{ Model layout } & Overall performance & High flow & Medium flow & Low flow \\
\cline { 2 - 5 } & MRAE & MRAE & MRAE & MRAE \\
\hline $\begin{array}{c}\text { Lumped Model } \\
3 \text { sub division } \\
\text { Model }\end{array}$ & 0.640 & 0.478 & 0.654 & 0.736 \\
$\begin{array}{c}6 \text { sub division } \\
\text { Model }\end{array}$ & 0.580 & 0.477 & 0.609 & 0.583 \\
$\begin{array}{c}9 \text { sub division } \\
\text { Model }\end{array}$ & 0.611 & 0.435 & 0.688 & 0.497 \\
$\begin{array}{c}16 \text { sub division } \\
\text { Model }\end{array}$ & 0.646 & 0.483 & 0.729 & 0.497 \\
\hline
\end{tabular}




\subsection{Comparison of the model performance}

In a restricted modelling situation like in watershed subdivision, it was difficult to conserve the water balance because of the model uncertainty and due to channel routing losses and evaporation losses. To overcome this situation for comparative purpose Nash-Sutcliffe and annual water balance were also checked but for low and medium flow simulation, the main focus was on MRAE objective function. Result shows that (Figure 12) the six subdivision model gives better results as compared to the others.

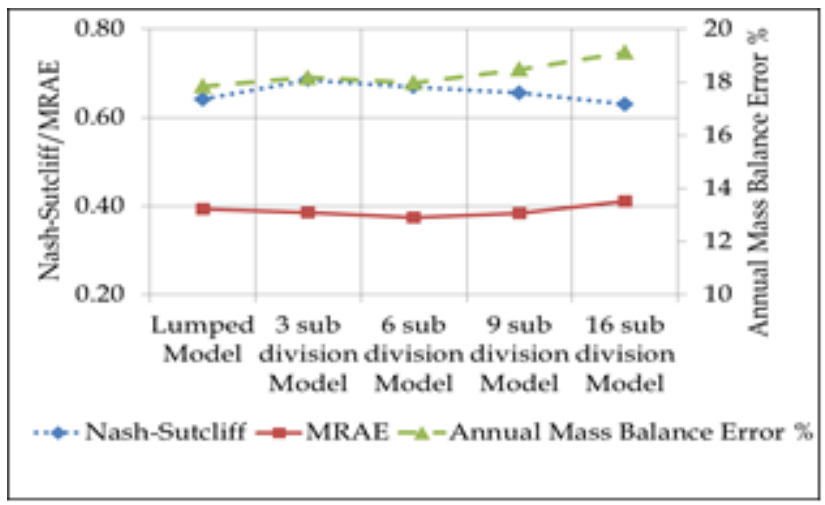

Figure 12: Models performance comparison in calibration period

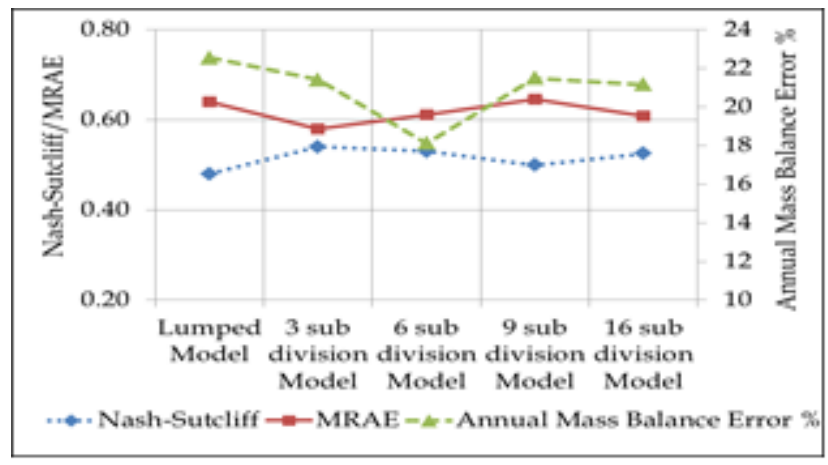

Figure 13: Models performance comparison in validation period

\subsection{Antecedent moisture condition result}

Antecedent moisture condition analysis has been done from 1 Jan 2010 to 31 Dec 2013. For calibration period, data has been selected for HEC HMS from 1 Dec-2010 to 9 Dec 2010, for validation 9 Jan 2011 to 17 Jan 2011.The calibration and validation data values show the AMCIII condition, since we are interested in flood management when the soil is fully saturated under AMCIII condition. The widely used NASH Sutcliffe coefficient of efficiency.

Table 7: Result for calibration and validation period

\begin{tabular}{ccc}
\hline AMC & Calibration period (Nash) & Validation period (Nash) \\
\hline AMCIII & 0.708 & 0.573 \\
AMCII & 0.416 & 0.29 \\
AMCI & -0.16 & 0.24 \\
\hline
\end{tabular}




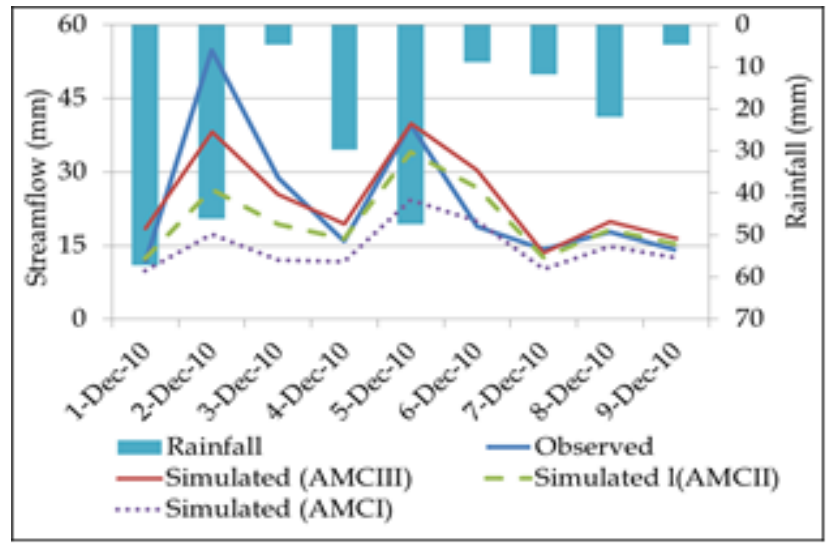

Figure 14: Result for calibration period

Table 8: Result for calibration and validation period

\begin{tabular}{ccc}
\hline AMC & Calibration period (Nash) & Validation period (Nash) \\
\hline AMCIII & 0.708 & 0.573 \\
AMCII & 0.416 & 0.29 \\
AMCI & -0.16 & 0.24 \\
\hline
\end{tabular}

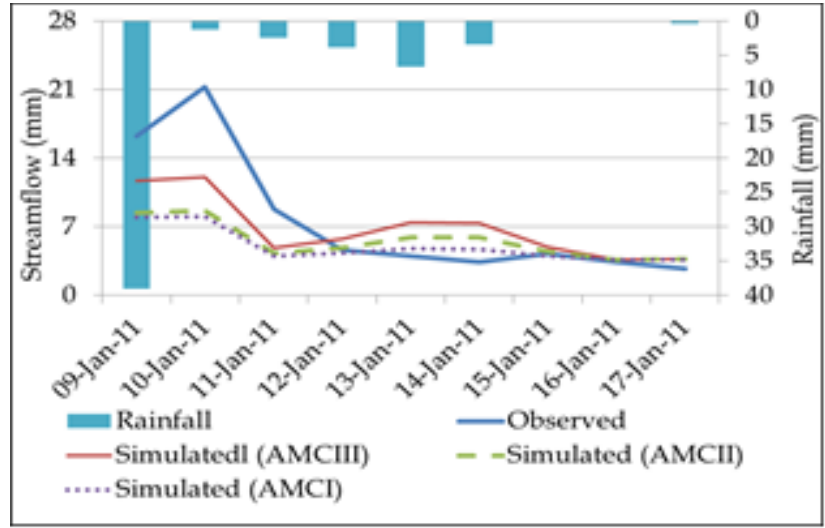

Figure 15: Result for calibration period

\section{DISCUSSION}

In this study, data was collected from January 2005 to December 2013 but in year 2009, there was a nine month missing data period, and therefore year 2009 data was excluded from hydrological modeling. The remaining data set was separated for calibration and validation period. The statistical analysis is likely to be biased when more than $10 \%$ of data are missing [14].

In this study, the main focus was on MRAE objective function for low flow and medium flow conditions because this gives better representation when contrasting data are present in the observed data set. Jayadeera (2016) [15] stated that MRAE measures the error with respect to each observed streamflow value and MRAE is more suitable for continuous model simulations targeting water resources management. Wijesekera \& Abeynayake (2003) [9] also used MRAE objective function for medium flow and low flow simulation. Legates \& McCabe (1999) [16] used Mean Absolute Error (MAE) objective function and stated that it is a balanced consideration of the high-and low-flows but 
(MAE) the average magnitude of the model error (accuracy) and taking the absolute value avoids error compensation, but does not indicate the direction of the deviation.

This study focused on the implication of antecedent moisture on the simulation of flood events when AMC-III condition occurred. The widely used Nash Sutcliffe coefficient of efficiency (NSE) was adopted as the objective function. Pathiraja et al. (2012) [17] also used NSE as objective function to determine the role of Antecedent moisture condition on the simulation of heavy flood events.

To find the optimum parameter range for sensitivity analysis, automatic calibration and manual calibration in HEC-HMS were attempted and global optimization was achieved. Sensitivity analysis has been done for lumped model to find the most sensitive parameters among all the parameters considered. Following sensitivity analysis among all parameters, soil percolation is the most sensitive parameter which triggers the highest percent change in the runoff value $(43.09 \%$ and with $66.67 \%$ change in parameters) and the tension storage is the least sensitive parameter with runoff change $3.31 \%$ with the same change in parameters. Sensitivity analysis in the research work of Rahul \& Manoj K, (2015) [18] shows that soil percolation is the most sensitive parameter in rank 1 and soil percolation parameter in rank 2 is the next sensitive parameter. In contrast, the research work by Kanchanamala, Herath \& Nandalal (2016) [19]for identifying impact of catchment scale on runoff did not consider sensitivity analysis for optimum parameter estimation but in the present study, sensitivity analysis was used to recognize the optimum range of the parameters with automatic and manual calibration and then verified it with global optimization.

In this study with HEC-HMS, 3-, 6-, 9- and 16- subdivision models were calibrated and validated. Accuracy level increased up to 6 sub division case with MRAE value for objective function of $0.385,0.375,0.384$ and 0.411 , respectively but with Nash objective function, the coefficient value for calibration run was $0.685,0.669,0.656$ and 0.630 , respectively. Overall performance among 3-, 6, 9-, 16- subdivision models, the accuracy increased up to 6 subdivision model (with MRAE of 0.375) by $4.687 \%$ as compared to the lumped model (MRAE 0.393) in calibration period. Annual mass balance error in lumped model was $17.85 \%$ but in case of subdivision model, 6-subdivision model gives good results in terms of annual mass balance error which is 17.98 as compared to the other sub division models.

For validation runs, the accuracy increased up to 3- subdivision model and decreased up to 9and for 16-, the accuracy slightly increased again with MRAE of 0.580, 0.611, 0.646 and 0.609, respectively. For validation runs, the accuracy decreased up to 9- and increased for 16- subdivision model, with Nash values of $0.540,0.530,0.499$ and 0.525 , respectively. The overall performance among 3-, 6-, 9-,16-subdivision models, the 6-subdivision model with MRAE and Nash values of $4.636 \%$ and 0.669 , respectively produced better results. The annual mass balance error in lumped model was $22.545 \%$ and in distributed model, 6- subdivision model gives the best simulation results in terms of annual mass balance error which is $18.122 \%$.

In 6-subdivision model, for the estimated high flow and medium flow, the level of accuracy increased by $(1.671 \%$ and $1.795 \%$, respectively) with MRAE 0.353 and 0.383 , respectively for calibration period but accuracy for low flow is higher in 9- subdivision model which increased to $22.507 \%$. But the overall performance accuracy for low flow was as less as $2.28 \%$ with MRAE (0.384). Norris \& Haan (1992) [20] also demonstrated the impact of various levels of watershed subdivision on simulated runoff hydrographs up to a particular threshold level; any further subdivision produced only a little change in runoff hydrograph generation. According to the results, the accuracy of the model slightly increased up to 6- subdivision model and then reduced 6- to 16- sub divisions showing the similarity with the research of Kanchanamala, Herath, \& Nandalal (2016) [19]. Their main focus was on the selection of the best model and their study was mainly targeted at flood management. But in the present study, calibration and validation of the model was performed to check the overall performance for water resource management. Thus, the main focuse was on MRAE objective function but for in for the controlled situations like in subdivision cases of watershed to reduce the uncertainty in mass balance error, the Nash Sutcliffe coefficient was also checked. 
Results with Antecedent moisture condition accuracy increased by $12.04 \%$ in lumped model with NASH value of 0.709 for AMC-III as compares to AMC-II with Nash values of 0.416 in calibration period. Accuracy increased by $6.60 \%$ with NASH values of 0.573 for AMC-III as compared to AMC-II with NASH values of 0.29 for validation. The results show that AMC-III gives a better simulation output as compared to existing CN method. Similarly Geetha, Surendra, Eldho, \& Rajendra (2007) [21] proposed two new modified models based on the existing SCS-CN concept for hydrological simulation, and the model described that the existing $\mathrm{CN}$ changes with the variation of AMC. In this study, the results show that AMC-III consideration is much important when soil is fully saturated. Similarly Pathiraja, Westra, \& Sharma (2012) [17] stated that the role of antecedent conditions on runoff is an important consideration in flood modeling, particularly in arid areas in which there is a large difference in terms of catchment discharge properties between dry and wet periods. The importance of the Antecedent moisture condition has been mentioned by Pathiraja et al. (2012) [17] and it was noted that as expected, the short-memory day to day had the greatest impact on the resulting flood, due to the accuracy of flood estimates improving by roughly $20 \%$ when 2 days of prior rainfall were considered compared to none. Further, the analysis shows that there is a consistent underestimation of the design flood events when antecedent moisture is not properly simulated, which can be as much as $30 \%$ when only 1 or 2 days of antecedent rainfall are considered .According to this study, the analysis has been done incorporating rainfall prior to up to 5 days and AMC-III is prevalent as compared to AMC-II in Badalgama catchment. Therefore the above results clearly show that accuracy of the model increased with AMC-III condition.

\section{CONCLUSION AND RECOMMENDATION}

The use of subdivision of watersheds for semi-distributed modeling resulted in a slight improvement in prediction of low flow and medium flow. Improvements generally disappeared when the number of subdivisions reached a relatively small number, in between six and sixteen sub-watersheds in the present study. Watershed subdivision multiplies the number of model parameters to be estimated as compared to the lumped model, therefore discriminating parameter values between a higher number of subdivisions is difficult to be justified from a technical perspective. Further, incorporating a higher number of subdivisions, as implemented in HEC-HMS, was strenuous and time-consuming.

As the result shows in the AMC analysis, AMC-III gives more reliable results as compared to AMC-II. The AMC-II was calculated by using watershed characteristics and the base model used AMC-II condition with associated $\mathrm{CN}$. This might possibly give inaccurate results when soil is fully saturated. In this research, the recession method was considered for base flow estimation, and that led to a mass balance error exceeding $20 \%$. Therefore it is recommended that for improved accuracy, linear reservoir method should be considered as base flow generation to conserve the water balance. In this research, stream network is considered for watershed subdivisions and therefore for further accuracy, it is recommended that land use and slope should also be considered Modelers should consider AMC-III especially for the design of structures under saturated soil conditions.

\section{ACKNOWLEDGEMENT}

The authors are grateful to the UNESCO Madanjeet Singh Center for South Asia Water Management (UMCSAWM) and the South Asia Foundation (SAF) for hosting the first author in the international Master's Degree program in Water Resources Engineering and Management. The support given by the Irrigation Department of Sri Lanka by providing necessary data is thankfully acknowledged. 


\section{REFERENCES}

[1] Thompson, D. B., \& Cleveland, T. G. (2009). Subdivision of Texas Watersheds for Hydrologic Modeling.

[2] Minshall, N. E. (1960). Predicting Storm Runoff on Small Experimental Watersheds. Transactions of the American Society of Civil Engineers, 127(1), 625-645.

[3] Zhang, H. L., Wang, Y. J., Wang, Y. Q., Li, D. X., \& Wang, X. K. (2013). The effect of watershed scale on HEC-HMS calibrated parameters: a case study in the Clear Creek watershed in Iowa, US. Hydrol. Earth Syst. Sci., 17(7), 2735-2745.

[4] Wei, H., \& Zhang, Y. (2011). Effects of antecedent soil moisture on runoff modeling in small semiarid watersheds of southeastern Arizona. Hydrol. Earth Syst. Sci., 15(10), 3171-3179.

[5] Williams, J., \& LaSeur, W. (1976). Water yield model using SCS curve numbers. J Hydraul Div ASCE 102 (HY9), 1241-1253.

[6] Hawkins, R. H. (1978). Runoff Curve Numbers with Varying Site Moisture. Journal of the Irrigation and Drainage Division, 104(4), 389-398.

[7] Moeletsi, M. E., Shabalala, Z. P., Nysschen, G. D., \& Walker, S. (2016). Evaluation of an inverse distance weighting method for patching daily and dekadal rainfall over the Free State Province, South Africa. Water SA, 42(3), 466-474.

[8] Schaffenberg, W. . (2013). Hydrologic Modeling System HEC-HMS, User Manual: Version 4.0. U.S. Army Corps of Engineers, Hydrologic Engineering Center HEC, 609 Second Street, Davis, CA, USA.

[9] Wijesekera, N. T. ., \& Abeynayake, J. . (2003). Watershed similarity conditions for peak flow transition. A study of river basins in the wet zone of Sri Lanka,. Engineer Journal of the Institution of Engineers, Sri Lanka.

[10] McCuen Richard H., Knight Zachary, \& Cutter A. Gillian. (2006). Evaluation of the NashSutcliffe Efficiency Index. Journal of Hydrologic Engineering, 11(6), 597-602.

[11] De Silva, M. M. G. ., Weerakoon, S. ., \& Herath, S. (2014). Modeling of Event and Continuous Flow Hydrographs with HEC-HMS: Case Study in the Kelani River Basin, Sri Lanka |. Journal of Hydrologic Engineering, 19, No 4.

[12] Kumar, S., \& Merwade, V. (2009). Impact of Watershed Subdivision and Soil Data Resolution on SWAT Model Calibration and Parameter Uncertainty1. JAWRA Journal of the American Water Resources Association, 45(5), 1179-1196.

[13] Mishra, S. ., Jain, M. ., Suresh Babu, P., Venugopal, K., \& Kaliappan, S. (2008). Comparison of AMC-dependent CN-conversion Formulae. Water Resour Manage, 22, 1409-1420.

[14] Dong, Y., \& Peng, C.-Y. J. (2013). Principled missing data methods for researchers. SpringerPlus, 2.

[15] Jayadeera, P. . (2016). Development of a rainfall runoff model for kalu ganga basin of sri lanka using hec hms. UNESCO Madenjeet Singh Centre,University of Moratuwa.

[16] Legates, D. ., \& McCabe, J. G. J. (1999). Evaluating the use of "goodness-of-fit" measures in hydrologic and hydroclimatic model validation. Water Resources Researches, 35(1), 233241.

[17] Pathiraja, S., Westra, S., \& Sharma, A. (2012). Why continuous simulation? The role of antecedent moisture in design flood estimation. Water Resources Research, 48(6), W06534.

[18] Rahul, W., \& Manoj K, J. (2015). Continuous Hydrological Modeling using Soil Moisture Accounting Algorithm in Vamsadhara River Basin, India

[19] Kanchanamala, D. P. H. M., Herath, H. M. H. K., \& Nandalal, K. D. W. (2016). Impact of Catchment Scale on Rainfall Runoff Modeling: Kalu Ganga River Catchment upto Ratnapura. Engineer: Journal of the Institution of Engineers, Sri Lanka, 49(2), 1.

[20] Norris, G., \& Haan, C. . (1992). Impact of subdividing watersheds on estimated hydrographs. Transaction of the ASAE, 443-445. 
[21] Geetha, K., Surendra, M., Eldho, T. ., \& Rajendra, P. pande. (2007). Modifications to SCSCN Method for Long-Term Hydrologic Simulation. 